\title{
PERBANDINGAN STRUKTUR, FUNGSI, DAN NILAI BUDAYA PADA LEGENDA TELAGA NGEBEL PONOROGO DAN LEGENDA DANAU RANU PASURUAN
}

\author{
Nuraini Saura Putri \\ STKIP Bina Insan Mandiri \\ Email: nurainisaura@stkipbim.ac.id \\ Oktavian Aditya Nugraha \\ STKIP Bina Insan Mandiri \\ Email: oktavianaditya@stkipbim.ac.id
}

\begin{abstract}
Abstrak
Upaya melestarikan warisan budaya berupa legenda dan dalam rangka mencari identitas bangsa serta keberagaman suku bangsa yang ada di Indonesia, salah satu cara yang perlu dilakukan adalah mengumpulkan dan memelihara folklor. Penelitian ini sebagai sarana untuk memelihara foklor berupa legenda Danau Ranu dan legenda Telaga Ngebel. Kedua legenda tersebut memiliki cerita yang hampir sama, baik tokoh maupun jalan ceritanya. Tujuan penelitian ini dimaksudkan untuk mengetahui persamaan dan perbedaan dalam kedua legenda tersebut, melalui struktur, fungsi dan nilai budayanya. Adapun tujuan jangka panjang dalam penelitian ini yaitu, untuk memberikan pengetahuan mengenai penelitian sastra lisan terutama terhadap mahasiswa sastra yang dapat dijadikan acuan untuk kedepannya. Selain itu penelitian ini juga dapat memberikan pengetahuan baru bagi masyarakat umum mengenai jalan cerita legenda Telaga Ngebel dan legenda Danau Ranu. Berdasarkan hasil penelitian yang telah dilakukan maka dapat ditarik sebuah kesimpulan, yaitu: pada strukturnya terdapat empat persamaan dan memiliki tiga perbedaan. Sedangkan fungsi yang terkandung dalam dua legenda tersebut sama-sama mempunyai tiga fungsi yaitu; sebagai hiburan, sebagai alat legimasi pranata-pranata dan lembaga kebudayaan, sebagai alat pendidik anak. Untuk nilai budaya yang terkandung dalam dua legenda tersebut adalah nilai Diktatik, nilai Etika, dan nilai Religius.
\end{abstract}


Kata kunci: Struktur, Fungsi, Nilai Budaya, Sastra Lisan, Legenda

\begin{abstract}
Efforts to preserve the cultural heritage of legend and in order to find the identity of the nation and the diversity of ethnic groups that exist in Indonesia, one way to do is to collect and maintain folklore. This research as a means to maintain foklor in the form of Ranu Lake legend and Ngebel Lake legend. Both legends have almost the same story, both the character and the story. The purpose of this study is intended to determine the similarities and differences in both legends, through structure, function and cultural values. The long-term goal in this study is, to provide knowledge about oral literature research, especially against the student literature that can be used as a reference for the future. In addition, this research can also provide new knowledge for the general public about the storyline of the legend of Lake Ngebel and the legend of Lake Ranu. Based on the results of research that has been done then can be drawn a conclusion, namely: the structure there are four equations and has three differences. While the functions contained in the two legends have the same three functions namely; as entertainment, as a means of legitimizing institutions and cultural institutions, as child educators. For the cultural values contained in the two legends are the value of Dictation, Ethical values, and Religious values.
\end{abstract}

Keywords: Structure, Function, Cultural Values, Oral Literature, Legend

\title{
PENDAHULUAN
}

Dalam rangka mencari identitas bangsa dan keberagaman suku bangsa yang ada di Indonesia, salah satu cara yang perlu dilakukan adalah mengumpulkan dan memelihara folklor. Folklor merupakan suatu kebudayaan daerah yang harus dilestarikan. Folklor atau yang sering disebut dengan kebudayaan kolektif ini mengandung nilai sastra dan nilai edukasi yang tinggi terhadap masyarakat. Folklore adalah kebudayaan suatu kolektif yang tersebar dan diwariskan turun-temurun di antara kolektif macam apa saja, secara tradisional dalam versi yang berbeda, baik dalam bentuk lisan 202 | ISSN: 22477-5150, e-ISSN: 2549-2195 http://journal.unesa.ac.id/index.php/jpi 
maupun contoh yang disertai dengan gerak isyarat atau alat pembantu mengingat misalnya pada pertunjukan wayang (Danandjaja, 2007). Folklor sering dikaitkan dengan apa yang dinamakan sastra lisan, hal ini dikarenakan sastra lisan bagian dari folklor. Sastra lisan sebenarnya adalah kasusastraan yang mencangkup ekspresi kesusastraan warga suatu kebudayaan yang disebarkan dan diturun temurunkan secara lisan (dari mulut ke mulut). Legenda merupakan salah satu bentuk folklor lisan. Legenda adalah cerita prosa rakyat yang dianggap oleh empunya cerita sebagai suatu kejadian yang sungguh-sungguh pernah terjadi. Legenda sering dipandang sebagai "sejarah" kolektif (folk history), karena "sejarah" tidak tertulis maka mengalami distorsi, sehingga ceritanya sering jauh berbeda dengan kisah aslinya (Danandjaja, 2007).

Menurut Danandjaja (2007: 66) mengatakan legenda adalah cerita rakyat yang dianggap oleh yang mepunya cerita sebagai suatu kejadian yang sungguh-sungguh pernah terjadi. Selain itu legenda sering kali tersebar dalam bentuk pengelompokan siklus, yaitu sekelompok cerita yang berkisar pada satu tokoh atau kejadian tertentu. Legenda adalah cerita-cerita yang oleh masyarakat yang mempunyai cerita tersebut dianggap sebagai peristiwa-peristiwa sejarah. Itulah sebabnya ada yang mengatakan bahwa legenda adalah sejarah rakyat (Hutomo, 1991). Sebagian legenda menceritakan mengenai asal usul suatu tempat, seperti halnya yang menjadi kajian dalam penelitian ini mengenai legenda asal-usul suatu tempat. Struktur adalah hubungan antara unsur-unsur pembentuk dalam susunan keseluruhan. Hubungan antar unsur tersebut dapat berupa hubungan dramatik, logika, maupun waktu. Dalam struktur ada satuan unsur pembentuk dan susunannya. Unsur-unsur pembentuk itu merupakan 
satuan-satuan operasional yang dapat digunakan untuk keperluan penggalian, pengurangan, pengikhtiaran, dan lain-lain (Sudikan, 2001).

Menurut Sunardjo (1997) nilai-nilai budaya yang tinggi dapat dimanfaatkan bagi masyarakat umum, sedangkan bagi sejarah sastra lama akan dicatat bahwa sastra pada masa itu telah berisi nilai budaya yang berguna dalam kehidupan masyarakat atau dapat dijadikan teladan. Dalam kaitan itu sistem nilai budaya adalah sejumlah pandangan mengenai soalsoal yang paling berharga dan bernilai dalam hidup. Sistem nilai budaya menjiwai semua pedoman yang mengatur tingkah laku warga pendukung kebudayaan yang bersangkutan. Pedoman tingkah laku itu adalah adat istiadat, system norma, aturan etika, aturan moral, aturan sopan santun, pandangan hidup, ideologi pribadi (Daen, 2008).

Penelitian ini mengkaji Legenda Danau Ranu Pasuruan dan Legenda Telaga Ngebel Ponorogo. Legenda yang ada di kedua tempat tersebut mempunyai kemiripan cerita. Asal mula Danau maupun Telaga tersebut berasal dari air yang keluar dari sebuah lidi yang di tarik dari dalam tanah. Secara singkat Legenda Danau Ranu bercerita tentang seorang Begawan yang sangat sakti dan disegani warga bertemu dengan wanita cantik. Kecantikan wanita tersebut membuat Begawan mengeluarkan air suci yang biasa keluar dari seorang laki-laki. Secara sigap air suci tersebut dipegang dan dengan kuasa Tuhan berubah menjadi sebuah pagot (pisau kecil). Suatu ketika wanita cantik tersebut meminjam pisau pada Begawan, dengan berat hati Begawan meminjamkan pisau yang berasal dari air suci miliknya. Begawan meminjamkannya dengan syarat agar tidak meletakkan pisau tersebut dipangkuan, namun karena kelalaiannya dipangkulah pisau tersebut. pisau/ pagot tersebut lenyap dan membuat wanita tersebut hamil. Lahirlah seorang bayi yang menyerupai ular, untuk menyempurnakan 204 | ISSN: 22477-5150, e-ISSN: 2549-2195 http://journal.unesa.ac.id/index.php/jpi 
wujudnya sebagai manusia dia harus melakukan pertapaan. Ditengah pertapaannya ular tersebut dibantai oleh warga sebagai santapan. Mendengar hal tersebut wanita cantik marah dan membuat sayembara untuk menarik lidi bagi warga desa. Air besar keluar dari lidi yang dicabut dan menenggelamkan desa.

Pemilihan legenda Danau Ranu Pasuruan dan Telaga Ngebel Ponorogo sebagai kajian penelitian ini dengan alasan kedua tempat tersebut mempunyai cerita legenda yang hampir sama. Selain itu masyarakat di sekitar kedua lokasi penelitian masih percaya terhadap legenda yang ada, hal ini terbukti dengan masih adanya upacara larung pada setiap bulan Asyuro di kedua tempat tersebut. Dengan adanya penelitian ini diharapkan masyarakat luas dapat mengetahui serta membandingkan persamaan dan perbedaan legenda Danau Ranu dan Telaga Ngebel. Penelitian ini juga bertujuan untuk menjaga Legenda Danau Ranu dan Telaga Ngebel agar tetap diketahui oleh masyarakat luas. Adapun permasalahan yang dibahas pada penelitian ini, yaitu 1) Bagaimana struktur legenda Danau Ranu dan Telaga Ngebel? 2) Bagaimana fungsi legenda Danau Ranu dan Telaga Ngebel? 3) Bagaimana nilai budaya dalam legenda Danau Ranu dan Telaga Ngebel?. Penelitian ini bertujuan untuk mendeskripsikan struktur legenda Danau Ranu dan Telaga Ngebel, mendeskripsikan fungsi legenda Danau Ranu dan Telaga Ngebel, dan mendeskripsikan nilai budaya dalam legenda Danau Ranu dan Telaga Ngebel.

\section{PEMBAHASAN}

Membahas legenda sama halnya membahas tentang sejarah. Legenda Danau Ranu dan legenda Telaga Ngebel merupakan cerita 
mengenai asal-usul terjadinya suatu tempat. Di dalam legenda ini banyak sekali fungsi dan nilai yang bisa dijadikan teladan. Kedua legenda tersebut mempunyai cerita yang hampir sama, dengan adanya penelitian ini diharapkan pembaca mampu mengetahui perbedaan kedua legenda tersebut serta mampu meneladani fungsi dan nilai budaya yang terkandung di dalamnya. Berikut pemaparan Struktur, Fungsi, dan Nilai Budaya yang terdapat pada legenda Danau Ranu dan legenda Telaga Ngebel.

Struktur dalam legenda Danau Ranu mengisahkan seorang anak bernama Baru Klinting yang berwujud ular yang dibunuh oleh masyarakat desa Ranu untuk dijadikan hidangan. Struktur legenda Danau Ranu sebagai berikut:

1. Begawan Nyampo seorang yang sakti mandraguna dan bijaksana, tinggal di sekitar Kademangan Klindungan.

2. Endang Sukarni seorang putri keraton dari Kerajaan Mataram yang meninggalkan kerajaan dikarenakan suatu hal. Menemui Begawan Nyampo untuk mengabdi dan menjadi muridnya untuk memperoleh ilmu-ilmu kebijaksanaan.

3. Begawan Nyampo tterpesona akan kecantikan Endang Sukarni, tanpa disadari keluar air suci dari dalam dirinya dan kemudian dia ubah menjadi pisau kecil.

4. Endang Sukarni dilarang memangku pisau tersebut. Endang Sukarni melanggarnya sehingga menyebabkan dia hamil.

5. Endang Sukarni melahirkan anak yang berwujud ular, bernama Baru Klinting.

6. Baru Klinting bertapa untuk mendapatkan wujud sempurna sebagai manusia. 
7. Orang desa Kademangan Klindungan mengadakan selamatan untuk mendatangkan hujan, dengan hidangan daging ular (Baru Klinting).

8. Endang Sukarni menyamar sebagai pengemis meminta daging ular namun warga malah mengusirnya.

9. Seorang nenek memberi daging ular untuk Endang Sukarni.

10. Endang Sukarni menancapkan lidi ke dalam tanah, kemudian mengumumkan bagi yang merasa dirinya kuat dan sombong agar mencabut lidi tersebut.

11. Tidak ada seorang warga desa Klindungan yang mempu mencabutnya, kemudian Endang Sukarni sendiri yang mencabutnya.

12. Dari lubang bekas dicabutnya lidi tersebut keluarlah air yang sangat deras, hingga kademangan Klindungan tergenangi oleh air.

13. Genangan tersebut menjadi sebuah danau yang kemudian dinamakan Danau Ranu.

Terem adalah sebuah simbol yang dilengkapi dengan konteks masyarakat dan kesejarahannya. Terem dikategorikan menjadi peran tunggal dan peran ganda. Terem dalam legenda Danau Ranu dapat dilihat sebagai berikut. a: Kademangan Klindungan, $a_{1}$ :Begawan Nyampo, $a_{2}$ :Endang Sukarni, $a_{3}$ :Baru Klinting. b:Tuhan Yang Maha Esa, c:Orang desa Klindungan, $c_{1}$ :orang desa, $c_{2}$ :nenek.

Fungsi ialah peranan yang dipegang oleh terem. Maka fungsi mempengaruhi terem. Peranan atau sifat dalam legenda Danau Ranu tergambar sebagai berikut. $\mathrm{x}$ : keburukan, $x_{1}$ : melanggat adat, $x_{2}$ :tidak patuh, $x_{3}$ :membunuh, $x_{4}$ :mengusir. y: kebaikan, $y_{1}$ :menyempurnakan diri, $y_{2}$ :bijaksana, $y_{3}$ :menolong, $y_{4}$ :berkorban. z: keadilan, $z_{1}$ :menghukum, $z_{2}$ :membalas. Kode khusus N: terbentuknya Danau Ranu. 
Alur berdasarkan Terem dan Fungsi. Alur dapat digambarkan melalui struktur terem dan fungsi ala Maranda sebagai berikut,

$\mathrm{N}=\left(a_{1}\right)_{y_{2}}:\left(a_{1}\right)_{x_{1}}+\left(a_{2}\right)_{x_{2}}:\left(a_{1}\right)_{x_{1}}:(b)_{z_{1}}::(b)_{z_{1}}:\left(a_{2}\right)_{x_{2}}::\left(a_{3}\right)$

$/ /\left\{\left(c_{1}\right)_{x_{3,4}}+\left(c_{2}\right)_{y_{3}}\right\}\left(a_{1}\right)_{x_{1}}:\left\{\left(a_{3}\right)_{y_{1}}+\left(c_{1}\right)_{x_{3}}\right\}:\left\{\left(a_{2}\right)_{z_{2}}+\left(c_{1}\right)_{x_{4}}\right\}:\left\{\left(a_{2}\right)_{z_{2}}:\left(c_{2}\right)_{y_{3}}\right\}:\left(x_{4}\right)^{c-1} / /$

berdasarkan formula tersebut dapat dijelaskan sebagai berikut. Begawan Nyampo $\left(a_{1}\right)$ yang bijaksana $\left(y_{2}\right)$ melanggar adat $\left(x_{1}\right)$, dan Endang Sukarni $\left(a_{2}\right)$ yang tidak patuh $\left(x_{2}\right)$ akhirnya mendapatkan kutukan atau hukuman $\left(z_{1}\right)$ dari Tuhan karena perilakunya. Endang Sukarni $\left(a_{2}\right)$ melahirkan anak yang menyerupai ular bernama Baru Klinting $\left(a_{3}\right)$. Baru Klinting $\left(a_{3}\right)$ berusaha menyempurnakan wujudnya $\left(y_{1}\right)$ sebagai manusia dengan cara bertapa. Saat melakukan pertapaan Baru klinting $\left(a_{3}\right)$ dibunuh $\left(x_{3}\right)$ oleh warga desa Klindungan $\left(c_{1}\right)$ dan dagingnya digunakan sebagai hidangan dalam selamatan desa. Endang Sukarni $\left(a_{2}\right)$ mendatangi selamatan desa untuk meminta daging ular yang diharapkan mampu mengembalikan wujud Baru Klinting $\left(a_{3}:\right)$, tetapi malah diusir $\left(x_{4}\right)$ oleh warga kampung $\left(c_{1}\right)$. Seorang nenek $\left(c_{2}\right)$ yang baik hati memberi sepotong daging ular $\left(y_{3}\right)$ untuk Endang Sukarni $\left(a_{2}\right)$.

Jika dilihat dari segi fungsinya, dapat disimpulkan bahwa fungsi keadilan terhadap suatu kehidupan tampak sangat menonjol. Kehidupan menggambarkan bahwa segala sesuatu yang didapat sesuai dengan hasil perbuatan. Kebaikan mendapatkan timbal balik yang baik bagi kehidupannya, begitu pula keburukan juga akan mendapatkan keburukan.

Struktur cerita legenda Telaga Ngebel yang mengisahkan seorang anak bernama Baru Klinting terlahir dengan wujud ular, kemudian dipotongpotong tubuhnya oleh masyarakat desa Ngebel untuk dijadikan hidangan. Struktur legenda Telaga Ngebel, sebagai berikut: 
1. Ki Ageng Mangir seorang yang sakti mandraguna dan bijaksana, tinggal di daerah Ngrowo.

2. Roro Kijang istri dari Ki Ageng Mangir, ikut merantau bersama.

3. Roro Kijang meminjam pisau ke Ki Ageng Mangir untuk membelah pinang.

4. Ki Ageng Mangir meminjamkan pisau pusaka.

5. Roro Kijang agar segera mengembalikan dan tidak boleh ditaruh dipangkuan. Roro Kijang melanggarnya.

6. Roro Kijang bersedih, dan merasa bersalah

7. Ki Ageng menerima dengan sabar hati, karena itu kehendak Tuhan.

8. Roro Kijang menerima segala kesalahan, dan menebusnya dengan bertapa di rawa. Semakin hari perutnya semakin besar.

9. Roro Kijang melahirkan seekor ular dengan kulit yang bercahaya, Roro Kijang malu, memasangi ular tersebut kelemting dan meninggalkannya.

10. Roro Kijang ditemui ular yang sudah semakin besar. Dia beri nama Baru Klinting.

11. Baru Klinting menemui Ki Ageng Mangir. Baru Klinting disuruh bertapa melingkari gunung wilis untuk menyempurnakan bentuk tubuhnya sebagai manusia.

12. Orang desa Ngebel mengadakan selamatan bersih desa dengan hidangan daging ular (Baru Klinting) yang mereka dapatkan dari menyayat daging ular di tengah hutan.

13. Baru klinting menyamar menjadi anak kecil yang penuh luka dan meminta makanan namun warga malah mengusirnya.

14. Seorang nenek memberi makan Baru Klinting. 
15. Baru Klinting menancapkan lidi ke dalam tanah, kemudian mengumumkan bagi yang merasa dirinya kuat dan sombong agar mencabut lidi tersebut.

16. Tidak ada seorang warga desa Ngebel yang mampu mencabutnya, kemudian Baru Klinting sendiri yang mencabutnya.

17. Dari lubang bekas dicabutnya lidi tersebut keluarlah air yang sangat deras, hingga desa Ngebel tergenangi oleh air.

18. Genangan tersebut menjadi sebuah telaga yang kemudian dinamakan Telaga Ngebel.

19. Baru Klinting kembali menemui Ki Ageng Mangir. Nama Baru Klinting diganti menjadi Joko Baru.

Terem adalah sebuah simbol yang dilengkapi dengan konteks masyarakat dan kesejarahannya. Terem dikategorikan menjadi peran tunggal dan peran ganda.

Terem dalam Telaga Ngebel dapat dilihat sebagai berikut.

$\alpha$ : Desa Ngorowo,

$a_{1}$ :Ki Ageng Mangir, $a_{2}$ :Roro Kijang, $a_{3}$ :Baru Klinting.

b: Tuhan Yang Maha Esa,

c: Orang desa Ngebel,

$c_{1}$ :orang desa, $c_{2}$ :nenek.

Fungsi ialah peranan yang dipegang oleh terem. Maka fungsi mempengaruhi terem. Peranan atau sifat dalam legenda Telaga Ngebel tergambar sebagai berikut.

x: keburukan,

$x_{1}$ : lalai $x_{2}$ : menyayat, $x_{3}$ : serakah, $x_{4}$ : mengusir.

y: kebaikan,

$y_{1}$ : sabar hati, $y_{2}$ : menyempurnakan diri, $y_{3}$ : menolong, 210 | ISSN: 22477-5150, e-ISSN: 2549-2195 http://journal.unesa.ac.id/index.php/jpi 
z: keadilan,

$z_{1}$ : menghukum, $z_{2}$ : membalas, $z_{3}$ : tenggelam, $z_{4}$ : selamat

Kode khusus N: terbentuknya Danau Ranu.

Alur berdasarkan Terem dan Fungsi. Alur dapat digambarkan melalui struktur terem dan fungsi ala Maranda sebagai berikut,

$\mathrm{N}=\left(a_{1}\right)_{y_{1}}+\left(a_{2}\right)_{x_{1}}::\left(a_{2}\right)_{x_{1}}:\left(a_{1}\right)_{z_{1}}::\left(a_{2}\right)_{x_{1}}:(b)_{z_{1}}::\left(a_{3}\right)$

//

$\left\{\left(c_{1}\right)_{x_{2,3,4}}+\left(c_{2}\right)_{y_{3}}\right\}:\left\{\left(a_{3}\right)_{y_{2}}+\left(c_{1}\right)_{x_{2}}\right\}:\left\{\left(a_{3}\right)_{z_{1}}+\left(c_{1}\right)_{x_{4}}\right\}:\left\{\left(a_{3}\right)_{z_{2}}+\left(c_{2}\right)_{y_{3}}\right\}::\left\{\left(c_{1}\right)_{z_{3}}+\left(c_{2}\right)_{z_{4}}\right\}$

//

berdasarkan formula tersebut dapat dijelaskan sebagai berikut. Ki Ageng Mangir $\left(a_{1}\right)$ yang sabar hati $\left(y_{1}\right)$ meminjamkan pisau pusaka terhadap istrinya Roro Kijang $\left(a_{2}\right)$ dengan syarat agar tidak meletakkannya dipangkuan. Roro Kijang $\left(a_{2}\right)$ lalai $\left(x_{1}\right)$ akhirnya Ki Ageng Mangir $\left(a_{1}\right)$ memberi hukuman $\left(z_{1}\right)$ dengan menyuruh Roro Kijang $\left(a_{2}\right)$ bertapa di rawarawa. Roro Kijang $\left(a_{2}\right)$ juga mendapat hukuman $\left(z_{1}\right)$ dari Tuhan atas kelalaiannya. Roro Kijang $\left(a_{2}\right)$ melahirkan seekor ular bernama Baru Klinting $\left(a_{3}\right)$. Baru Klinting $\left(a_{3}\right)$ berusaha menyempurnakan wujudnya $\left(y_{1}\right)$ sebagai manusia dengan cara bertapa. Saat melakukan pertapaan Baru klinting $\left(a_{3}\right)$ disayat $\left(x_{2}\right)$ oleh warga desa Ngebel $\left(c_{1}\right)$ dan dagingnya digunakan sebagai hidangan dalam bersih desa. Baru Klinting $\left(a_{3}\right)$ mendatangi selamatan desa dengan menyamar sebagai anak kecil yang penuh luka borok, dia datang untuk meminta daging ular yang diharapkan mampu mengembalikan wujudnya. Warga desa $\left(c_{1}\right)$ malah mengusirnya $\left(x_{4}\right)$. Seorang nenek $\left(c_{2}\right)$ yang baik hati menolongya $\left(y_{3}\right)$ dengan memberi sepotong daging ular untuk Baru Klinting $\left(a_{3}\right)$, ajaib borok di badan anak tersebut hilang. Baru Klinting $\left(a_{3}\right)$ membuat sayambera yang berakhir dengan munculnya sumber air yang 
besar hingga menenggelamkan $\left(z_{3}\right)$ orang-orang desa $\left(c_{1}\right)$, nenek $\left(c_{2}\right)$ yang telah menolong Baru Klinting $\left(a_{3}\right)$ selamat $\left(z_{4}\right)$.

Jika dilihat dari segi fungsinya, dapat disimpulkan bahwa fungsi keadilan terhadap suatu kehidupan tampak sangat menonjol. Kehidupan menggambarkan bahwa segala sesuatu yang didapat sesuai dengan hasil perbuatan. Roro Kijang yang lalai mendapat hukuman dari Ki Ageng Mangir untuk bertapa di rawa, serta mendapat hukuman dari Tuhan dengan melahirkan seekor ular. Warga desa yang serakah, berburu (menyayat) serta mengusir anak dihukum dengan tenggelam oleh luapan air, nenek yang telah menolong selamat dari luapan air.

Analisis fungsi legenda Danau Ranu didasarkan pada teori fungsi yang dikemukakan oleh William $\mathrm{R}$ Bascom yang meliputi tiga fungsi sebagai berikut.

Pertama fungsi legenda sebagai hiburan. Sebuah hiburan dapat diperoleh dari berbagai media dan tempat, dengan cara pergi ke berbagai tempat wisata ataupun dengan menonton televisi dan mendengarkan dongeng. Dalam legenda Danau Ranu, fungsi hiburan terlihat melalui cerita kesaktian para tokoh. Seperti pada kutipan berikut ini,

Diantaranya pernah suatu ketika waktu Baru Klinting disuruh mencari air dengan menggunakan keranjang berlubang besar, namun hal itu sia-sia berkat kecerdikan yang dimilikinya. Keranjang tersebut di lapisi dedaunan yang dilekatkan dengan air liurnya. Baru Klinting juga pernah disuruh untuk bertempur dengan buaya putih di sungai Berdadung-Jember dengan alasan buaya putih tersebut sering mengganggu perjalanan orangorang. Baru Klinting pun berangkat menemui buaya putih dengan tergesa-tergesa, akibatnya saat melintasi sebuah gunung maka runtulah puncak gunung tersebut (tugel-Jawa) karena sebetan ekornya. Gunung itu kini bernama gunung Tugel 
yang berada di daerah Tongas-Probolinggo. Saat bertempur melawan buaya putih Baru Klinting menang dengan mudah. Tubuh buaya putih tersebut dipotong-potong dan dilemparkan kesana kemari.

Berdasarkan kutipan di atas bisa dilihat kesaktian Baru Klinting. Tokoh Baru Klinting tergambarkan sebagai tokoh yang cerdik dan sakti. Meruntuhkan gunung ketika melintas dan menjadikannya Gunung Tugel juga bagian dari cerita yang menghibur.

Sebagai alat legitimasi pranata-pranata dan lembaga-lembaga kebudayaan. Legenda Danau Ranu juga mengandung fungsi sebagai alat pengesahan pranata-pranata kebudayaan. Terdapat dua pranata sosial yang mampu menjadi nilai budaya masyarakat setempat, yaitu berkenaan dengan hubungan laki-laki dan perempuan serta upacara adat Distrikan yang dilakukan tiap tahunnya. Seperti,

Bertahun-tahun dalam kehidupan suci yang dijalaninya ternyata tidak menghapus sifat sejati manusia untuk tertarik terhadap lawan jenisnya, apalagi kini hampir setiap hari dapat melihat seorang putri yang cantik jelita. Sifat kelakiannya yang bertahun-tahun di pendam dalam benteng dan lelaki suci akhirnya tak tertahankan. Suatu ketika tiupan angin menyikap pakaian Endang Sukarni yang sedang mengantarkan makanan kepadanya, si Begawan pun tertegun melihatnya, darahnya berdesir, degup jantungnya tidak karuan, di hatinya berkecamuk perasaan yang selama ini di kubur dalam-dalam. Tanpa sadar keluarlah air suci dari dalam tubuhnya. Air suci yang biasa keluar dari seorang laki-laki yang sedang tenggelam dalam lengganan asmara dengan serta merta air suci tersebut disambarnya dan di genggam erat-erat. 
Berdasarkan kutipan di atas dapat diketahui antara laki-laki dan wanita harus mampu menjaga kesyahwatannya. Dari cerita tersebut mampu sebagai pengatur pranata, agar wanita dan laki-laki dapat menjaga diri. Seberapapun kesaktian dan keimanan seseorang jiwa kelaki-lakian seseorang akan tetap ada dalam dirinya. Sebagai seorang wanita harus mampu menjaga tingkah lakunya.

Legenda Danau Ranu juga mampu membawa masyarakatnya melestarikan kebudayaan dengan melakukan upacara adat Distrikan yang dilakukan setiap bulan Asyuro. Upacara ini dilakukan sebagai penghormatan dan mengenang peranan Begawan Nyampo, Endang Sukarni, dan Baru Klinting terhadap adanya Danau Ranu.

Sebagai alat pendidikan anak. Setiap cerita atau dongeng, legenda maupun mitos pasti mempunyai nilai yang dapat dijadikan suri tauladan. Dalam legenda Danau Ranu terdapat nilai yang mampu dijadikan alat pendidikan bagi anak. Pesan moral yang dapat dijadikan sebagai alat pendidikan anak diantaranya, kepatuhan tokoh Baru Klinting terhadap orang tuanya. Patuh terhadap orang tua membuat Baru Klinting mampu mengahadapi segala rintangan saat melakukan pertapaan. Seperti pada kutipan berikut ini,

Diantaranya pernah suatu ketika waktu Baru Klinting disuruh mencari air dengan menggunakan keranjang berlubang besar, namun hal itu sia-sia berkat kecerdikan yang dimilikinya.

Baru Klinting juga pernah disuruh untuk bertempur dengan buaya putih di sungai Berdadung-Jember dengan alasan buaya putih tersebut sering mengganggu perjalanan orang-orang. 
Menurut si Begawan kini tinggal satu cara yaitu memerintahkannya untuk bertapa di hutan dengan alasan untuk memperoleh kesempurnaan menjadi seorang manusia. Berdasarkan cerita tersebut kita dapat mengajarkan bahwa jika seseorang berbuat baik terutama menolong sesama akan mendapatkan hal yang baik pula bagi dirinya.

Analisis fungsi legenda Telaga Ngebel didasarkan pada teori fungsi yang dikemukakan oleh Bascom yang meliputi tiga fungsi.

Sebuah hiburan dapat diperoleh dari berbagai media dan tempat, dengan cara pergi ke berbagai tempat wisata ataupun dengan menonton televisi dan mendengarkan dongeng. Dongeng sering kali diceritakan oleh para orang tua, baik saat bersantai ataupun menjelang tidur. Selain dongeng, asal-usul nama desa, legenda atau mitos suatu tempat juga biasa diceritakan oleh guru kepada siswanya. Seperti legenda Telaga Ngebel berikut ini,

Kemudian lupa pesan suaminya dan pisau pusaka itu ditaruh di atas pangkuannya, tetapi apa yang terjadi ia amat terkejut dan heran karena pisau di atas pangkuannya seketika itu hilang musnah dicari kesana kemari tidak ada.

Dengan ratap dan tangis ia menceritakan apa yang terjadi dan yang telah dialami kepada Ki Ageng Mangir. Suaminya menerima kejadian itu dengan sabar hati, karena hal itu sudah menjadi kehendak Tuhan dan untuk menebus kesalahannya ini Roro Kijang harus bertapa di tengah tengah Rawa.

Diceritakan bahwa Roro Kijang perutnya makin hari semakin bertambah besar seperti orang bunting.

Hilangnya pisau pusaka yang dipangku, dan membuat tokoh Roro Kijang hamil merupakan bagian dari hiburan dalam cerita legenda Telaga Ngebel. 
Hal-hal yang bersifat mistis dan sakti mandraguna merupakan hiburan bagi pembaca.

Legenda Telaga Ngebel juga mengandung fungsi sebagai alat pengesahan pranata-pranata kebudayaan. Kebudayaan memiliki pranata sosial seperti tolong menolong, kerjasama, kesepakatan, dan perjanjian. Kebudayaan kesepakatan terdapat dalam legenda Telaga Ngebel. Hal tersebut dapat kita lihat dalam kutipan berikut ini.

Solokantoro mau mengaku sebagai ayahnya, tetapi sebelumnya harus menurut perintahnya dahulu yaitu : Lingkarilah Gunung Wilis ini kalau dari ujung ekor sampai kepalamu cukup panjang untuk melingkari Gunung Wilis ini rnaka akan diterima sebagai anaknya

Kutipan di atas mengandung fungsi sebagai alat pengesahan pranata kebudayaan yang bersifat kesepakatan. Tergambarkan kesepakatan antara seorang anak dan ayahnya, bahwa si anak akan diakui sebagai anak jika ia mampu melingkari Gunung Wilis. Hal tersebut dilakukannya dengan penuh perjuangan.

Fungsi selanjutnya dalam legenda Telaga Ngebel dapat digunakan sebagai alat pendidikan. Legenda ini dapat diceritakan kepada anak-anak, tidak hanya di sekolah namun juga di luar sekolah. Mengungkapkan asalusul sebuah tempat, dapat menjadi sebuah pengetahuan baru untuk anakanak.

Atas pesan dan saran Ibunya yaitu Roro Kijang. Baru Klinting disuruh menyusul dan mencari orang tuanya yang sedang bertapa digunung Wilis.

Solokantoro mau mengaku sebagai ayahnya, tetapi sebelumnya harus menurut perintahnya dahulu yaitu "Lingkarilah Gunung Wilis ini kalau dari ujung ekor sampai kepalamu cukup panjang untuk melingkari Gunung Wilis ini maka akan diterima sebagai anaknya". Dengan ridho Tuhan 216 | ISSN: 22477-5150, e-ISSN: 2549-2195 http://journal.unesa.ac.id/index.php/jpi 
Yang Maha Kuasa maka Baru Klinting dapat melingkari kaki Gunung, ekor di depan sang pertapa dan kepala sampai menyentuh ekor tetapi tinggal sepanjang jari saja.

Pesan moral yang dapat dijadikan sebagai alat pendidikan anak diantaranya, kepatuhan tokoh Baru Klinting terhadap orang tuanya. Patuh terhadap orang tua membuat Baru Klinting mampu menyempurnakan wujudnya menjadi manusia.

Nilai budaya dalam legenda Danau Ranu dianalisis menggunakan konsep budaya milik Latini. Latini membagi nilai budaya menjadi tiga (1) nilai didaktik, (2) nilai etika, (3) nilai religius.

Legenda Danau Ranu memiliki nilai dikdaktik yaitu ajaran agama, budi pekerti, ajaran kesempurnaan diri, ajaran agama bagaimana cara-cara mengabdi raja, ajaran tentang kepahlawanan dan ketatanegaraan. Kutipan, sebagai berikut.

Dahulu kala ada sebuah kedemungan yang sejahtera yang terkenal alamnya yang subur ditambah dengan pemandangan yang elok oleh birunya pegunungan Tengger di sebelah selatan dan kehidupan warganya begitu tentram, segala permasalahan bisa diselesaikan dengan baik. Hal itu karena adanya seorang Begawan yang sakti mandraguna dan bijaksana yang tinggal di sekitar Kedemangan. Begawan itu begitu dihormati dan disegani, orang memanggilnya "Begawan Nyampo".

Kutipan di atas menggambarkan mengenai nilai diktatik cara mengabdi terhadap orang yang disegani dan dianggap sakti. Penghormatan warga sekitar terhadap Begawan Nyampo yang dianggap sakti dan bijaksana.

Nilai etika dalam legenda Danau Ranu mengenai hubungan sebab akibat dari sifat-sifat baik dan buruk manusia. Perbuatan baik akan mendapat balasan kebaikan pula, sedangkan perbuatan buruk akan 
mendapatkan keburukan pula. Dalam nilai etika meliputi tiga aspek yaitu (1) aspek kesetiaan, (2) aspek ketaatan, (3) aspek kejujuran. Kutipan berikut menggambarkan aspek ketaatan tokoh Baru Klinting terhadap orang tuanya.

Baru Klinting juga pernah disuruh untuk bertempur dengan buaya putih di sungai Berdadung-Jember dengan alasan buaya putih tersebut sering mengganggu perjalanan orangorang.

Maka berangkatlah Baru Klinting untuk bertapa di hutan untuk beberapa waktu lamanya.

Ketaatan Baru Klinting terhadap ayahnya menjadi gambaran nilai etika pada legenda Danau Ranu. Ketaatan Baru Klinting membuahkan hasil dengan mampu merubah wujudnya menjadi seorang manusia.

Nilai religius dalam legenda Danau Ranu berhubungan dengan kepercayaan atau keyakinan seseorang terhadap agama, Tuhan atau hal-hal yang berada di luar kemampuan manusia. Aspek religius dalam legenda Danau Ranu tergambarkan melalui tokoh Begawan Nyampo. Begawan diartikan sebagai kedudukan yang dianggap suci.

Nilai didaktik adalah nilai yang berhubungan dengan ajaran tentang agama, budi pekerti, ajaran, kesempurnaan diri, ajaran cara-cara mengabdi raja, kepahlawanan, dan ketatanegaraan. Dalam legenda Telaga Ngebel terdapat nilai diktaktik yang berkaitan dengan budi pekerti. Berikut kutipan legenda Telaga Ngebel yang menggambarkan nilai didaktik.

Suaminya menerima kejadian itu dengan sabar hati, karena hal itu sudah menjadi kehendak Tuhan. Untuk menebus kesalahannya Roro Kijang harus bertapa di tengahtengah rawa. 
Pada kutipan di atas bisa diketahui nilai dikdaktik yang terkandung dalam legenda Telaga Ngebel. Nilai dikdaktik yang tergambrkan adalah nilai budi pekerti dimana seseorang yang telah melakukan kesalahan harus mengakuinya dan berani menanggung resiko atas apa yang telah ia lakukan.

Nilai etika dalam legenda Telaga Ngebel mengenai hubungan sebab akibat dari sifat baik dan buruk manusia. Perbuatan baik akan mendapat balasan kebaikan pula, begitu pula sebaliknya perbuatan buruk akan mendapatkan keburukan pula. Nilai etika meliputi tiga aspek yaitu (1) aspek kesetiaan, (2) aspek ketaatan, (3) aspek kejujuran. Legenda Telaga Ngebel terdapat dua aspek yaitu aspek ketaatan dan aspek kejujuran. Seperti kutipan berikut ini, menggambarakan nilai etika pada aspek ketaatan.

Dengan ridho Tuhan Yang Maha Kuasa maka Baru Klinting dapat melingkari kaki Gunung, ekor di depan sang pertapa dan kepala sampai menyentuh ekor tetapi tinggal sepanjang jari saja. Untuk mencapai ekomya maka dengan seijinnya Baru Klinting mengeluarkan lidahnya dengan sepanjang-panjangnya sampai ke ujung ekor

Ketaatan tokoh Baru Klinting terhadap ayahnya tergambar melalui kutipan di atas. Baru Klinting taat terhadap perintah ayahnya demi mendapat pengakuaan sebagai seorang anak. Ketaatannya juga memberikan dampak baik baginya, yaitu untuk menyempurnakan wujudnya sebagai manusia.

Nilai religius dalam legenda Telaga Ngebel berhubungan dengan kepercayaan atau keyakinan seseorang terhadap agama, Tuhan atau hal-hal yang berada di luar kemampuan manusia. Berikut ini kutipan nilai religius yang tergambar pada legenda Telaga Ngebel.

Suaminya menerima kejadian itu dengan sabar hati, karena hal itu sudah menjadi kehendak Tuhan. 
Dengan ridho Tuhan Yang Maha Kuasa maka Baru Klinting dapat melingkari kaki Gunung, ekor didepan sang pertapa dan kepala sampai menyentuh ekor tetapi tinggal sepanjang jari saja.

Nilai religius yang tergambar dari kutipan di atas terlihat bahwa tokoh dalam cerita legenda Telaga Ngebel mempercayai segala yang terjadi adalah kehendak Tuhan Yang Maha Kuasa.

\section{SIMPULAN}

Berdasarkan hasil penelitian yang telah dilakukan maka dapat ditarik sebuah kesimpulan, yaitu: pada strukturnya terdapat empat persamaan dan memiliki tiga perbedaan. Sedangkan fungsi yang terkandung dalam dua legenda tersebut sama-sama mempunyai tiga fungsi yaitu; sebagai hiburan, sebagai alat legimasi pranata-pranata dan lembaga kebudayaan, sebagai alat pendidik anak. Untuk nilai budaya yang terkandung dalam dua legenda tersebut adalah nilsi Diktstik, nilai Etika, dan nilai Religius.

Kesamaan yang terdapat pada legenda Telaga Ngebel dan Danau Ranu terdapat pada (1) kesamaan nama tokoh, yaitu Baru Klinting. Selain itu Baru Klinting sama-sama berasal dari sebuah pisau pusaka yang tanpa sengaja dipangku oleh seorang wanita, yang akhirnya membuat dia hamil. (2) Baru Klinting melakukan pertapaan untuk menyempurnakan wujudnya sebagai manusia, (3) terdapat sebuah sayembara untuk mencabut sebuah lidi, dan tak seorang pun dapat mencabutnya kecuali si pembuat sayembara. Lidi yang telah dicabut akhirnya menyemburkan air hingga menenggelamkan seluruh desa. (4) hanya dua orang yang selamat yaitu si pembuat sayembara, dan nenek tua yang telah memberi makan.

Perbedaan yang terdapat dalam dua legenda tersebut (1) terdapat dua nama tokoh yang berbeda, di dalam legenda Danau Ranu seorang yang 220 | ISSN: 22477-5150, e-ISSN: 2549-2195 http://journal.unesa.ac.id/index.php/jpi 
meminjamkan pisau pusaka bernama Begawan Nyampo, sedang di dalam legenda Telaga Ngebel bernama Ki Ageng Mangir. Tokoh yang berperan memangku pisau pusaka di dalam legenda Danau Ranu bernama Endang Sukarni sedangkan legenda Telaga Ngebel bernama Roro Kijang, (2) Hubungan antara kedua tokoh Endang Sukarni dan Begawan Nyampo pada legenda Danau Ranu, adalah seorang guru dan murid. Namun dalam legenda Telaga Ngebel hubungan Ki Ageng Mangir dan Roro Kijang adalah sepasang suami istri. (3) tokoh yang menyamar sebagai peminta makanan dalam legenda Danau Ranu adalah Endang Sukarni (ibu Baru Klinting) sedang dalam legenda Telaga Ngebel Baru Klinting sendiri yang menyamar.

Dari hasil penelitian bisa dilihat perbedaan dan persamaan legenda Telaga Ngebel dan Danau Ranu dari struktur ceritanya. Tokoh dan beberapa kejadian memiliki kesamaan. Asal-usul terbentuknya telaga maupun danau sama-sama berasal dari air yang keluar deras dari lidi yang dicabut oleh si pembuat sayembara.

\section{DAFTAR RUJUKAN}

Arifah, Dinillah dkk. 2007. Singgasana Raja yang Bergoyang (Kumpulan Cerita Rakyat Pasuruan). Pasuruan: Cipta Pustaka Utama.

Barthes, Roland. 2006. Mitologi. Yogyakarta: Kreasi Wacana.

Daen, Hans J. 2008. Manusia, Kebudayaan, dan Lingkungan. Yogyakarta: Pustaka Pelajar

Danandjaja, James. 2007. Foklor Indonesia. Jakarta: Pustaka Utama Grafiti. Hutomo, Suripan Sadi. 1991. Mutiara yang Terlupakan. Jatim: Himski Komisariat. 
Lantini, Susi Endah. 1997. Refleksi Nilai-nilai Budaya Jawa dalam Serat. Jakarta: Dekdikbud.

Sudikan, Setya Yuwana. 2001. Metode Penelitian Sastra Lisan. Surabaya: Citra Wacana.

Sudikan, Setya Yuwana. 2007. Antropologi Sastra. Surabaya: Unesa University Press.

Suyono. 1990. Cerita Asal-usul Nama Tempat sebagai Bahan dalam Sastra Indonesia. Surabaya: Jurusan Bahasa dan Sastra Indonesia.FBS.IKIP Surabaya. 